\title{
Intravitreal injection of a Rho-kinase inhibitor (fasudil) combined with bevacizumab versus bevacizumab monotherapy for diabetic macular oedema: a pilot randomised clinical trial
}

\author{
Hamid Ahmadieh, ${ }^{1}$ Ramin Nourinia ${ }^{2}$ Ali Hafezi-Moghadam, ${ }^{3,4}$ Hamideh Sabbaghi, ${ }^{5}$ \\ Shintaro Nakao, ${ }^{3,4,6}$ Souska Zandi, ${ }^{3,4,7}$ Mehdi Yaseri, ${ }^{1,8}$ Zahra Tofighi, ${ }^{1}$ Shadi Akbarian ${ }^{1}$
}

For numbered affiliations see end of article.

\section{Correspondence to} Professor Hamid Ahmadieh, Ophthalmic Research Center Labbafinejad Medical Center, Tehran 16666, Iran; hahmadieh@hotmail.com

$\mathrm{HA}$ and RN contributed equally.

This study was presented as a paper at the Retina Subspecialty Day and as a poster at the American Academy of Ophthalmology Annual Meeting, 2016, Chicago, USA.

Received 13 March 2018 Revised 1 July 2018 Accepted 26 July 2018 Published Online First 27 August 2018

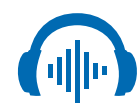

Listen to Podcast www.goo.gl/4cka77
Check for updates

(C) Author(s) (or their employer(s)) 2019. No commercial re-use. See rights and permissions. Published by BMJ.

To cite: Ahmadieh $\mathrm{H}$, Nourinia R, Hafezi-

Moghadam A, et al.

Br J Ophthalmol

2019:103:922-927.

\section{ABSTRACT}

Background/aims To compare the efficacy of combined intravitreal injection of bevacizumab and a Rho-kinase inhibitor, fasudil (intravitreal bevacizumab (IVB)/intravitreal fasudil (IVF)), with IVB alone for centreinvolving diabetic macular oedema (DME).

Methods In this prospective randomised clinical trial, 44 eyes with centre-involving DME were randomised into two groups. The combined group received three consecutive injections of IVB $(1.25 \mathrm{mg})$ and IVF $(50 \mu \mathrm{M} / \mathrm{L})$ monthly, while the monotherapy group received only one IVB $(1.25 \mathrm{mg})$ injection per month for 3 months. Changes in best-corrected visual acuity (BCVA) and central macular thickness (CMT) were compared between the two groups at months 3 and 6 . The primary outcome measure was the mean change in BCVA at month 6 . Results Mean BCVA was significantly improved in both groups at month $3(\mathrm{P}<0.001)$, but it persisted up to month 6 only in the IVB/IVF group. Improvement of $B C V A$ was greater in the IVB/IVF group at both time points $(P=0.008, P<0.001)$. In the IVB/IVF and IVB groups, $54.5 \%$ versus $10 \%$ of the eyes gained $\geq 15$ ETDRS letters at month $6(P=0.026)$. Between months 3 and 6 , mean BCVA significantly decreased by $5 \pm 7$ ETDRS letters in the IVB group ( $P=0.002)$, while no significant deterioration was observed in the IVB/IVF group. Corresponding with the BCVA changes, CMT was significantly reduced in both groups at month 3 $(p=0.006, p<0.001)$ but this reduction sustained only in the IVB/IVF group up to month $6(p<0.001)$.

Conclusion Adjunctive intravitreal injection of a Rho-kinase inhibitor may enhance and prolong the therapeutic effects of anti-vascular endothelial growth factor drugs for centre- involving DME.

\section{INTRODUCTION}

Diabetic macular oedema (DME) is the leading cause of decreased vision in patients with diabetes. ${ }^{1}$ Currently, anti-vascular endothelial growth factor (VEGF) agents are the main treatment modality for DME. ${ }^{2}$ This type of treatment, however, has some limitations. One of the principal mechanisms leading to an increase in retinal vessel permeability in patients with diabetes is endothelial cell damage. VEGF inhibition alone cannot control local inflammation and stop the endothelial damage induced by leucocytes. ${ }^{34}$
An in vitro study showed that upregulation of the Rho/Rho kinase (ROCK) pathway in diabetes promotes leucocyte adhesion to the microvasculature by affecting the expression of the adhesion molecules. ${ }^{5}$ A recent clinical study demonstrated that the serum levels of tumour necrosis factor (TNF)- $\alpha$ and its receptors were significantly elevated in patients with diabetes. TNF- $\alpha$-induced increased intercellular adhesion molecule-1 (ICAM-1) expression was significantly suppressed by ROCK inhibitors. ${ }^{6}$

Fasudil, as a ROCK inhibitor, has been shown to inhibit leucocyte-induced endothelial damage in both in vitro and in vivo studies. ${ }^{78}$ Two previous human studies have demonstrated the safety and efficacy of intravitreal injection of fasudil in patients with severe DME. ${ }^{9} 10$

The present pilot clinical trial was conducted to compare the efficacy of combined intravitreal injection of fasudil and bevacizumab with the efficacy of intravitreal injection of bevacizumab alone in the management of severe DME.

\section{METHODS \\ Participants}

In this prospective randomised controlled trial (RCT), 44 eyes of 44 patients with diabetes mellitus type 2 were recruited at Labbafinejad Medical Center, Tehran, Iran, from October 2014 to December 2015. Eyes with severe DME and best-corrected visual acuity (BCVA) $<70$ ETDRS letters equal to 20/40 Snellen visual acuity were included in this pilot RCT. Severe DME was defined as centre-involving macular oedema and centra subfield macular thickness $\geq 350 \mu \mathrm{m}$ associated with large cystoid changes with or without neurosensory detachment. ${ }^{1011}$ Patients with active proliferative diabetic retinopathy and those with a history of vitrectomy were excluded from the study. In addition, eyes with a history of intravitreal bevacizumab (IVB) injection and/or macular laser photocoagulation (MPC) during the past three months and eyes with a history of cataract surgery within the past six months were excluded. Furthermore, patients with glaucoma, vitreous haemorrhage, significant media opacity, traction on the macula or age-related macular degeneration were not included in this RCT. Pregnant women and patients with serum creatinine $\geq 3 \mathrm{mg} / \mathrm{dL}$ were excluded as well. This 
study was registered at ClinicalTrials.gov with the registration number NCT01823081.

Eligible subjects underwent comprehensive ophthalmic examination including BCVA assessment, anterior segment evaluation and tonometry. Meticulous fundus examination was conducted using a non-contact $78 \mathrm{D}$ lens. Spectral-domain optical coherence tomography (SD-OCT-1000; Topcon, Tokyo, Japan) with a $6 \times 6 \mathrm{~mm} 3 \mathrm{D}$ macular scan protocol was performed. The correct location of the central fovea was determined by an expert retina specialist using the colour fundus images. OCT was performed at baseline and at months 3 and 6. Fluorescein angiography (FAG, Heidelberg Engineering, Germany) was performed at baseline. The FAG images were evaluated according to the consensus of two independent graders blinded to the experimental treatments; the graders defined macular ischaemia as a foveal avascular zone (FAZ) wider than $1000 \mu \mathrm{m}$ and/or broken perifoveal capillary rings at the borders of the FAZ with distinct areas of capillary non-perfusion within one disc diameter of the foveal centre in the transit phase of FAG. ${ }^{12}$ Based on these criteria, diabetic macular ischaemia was identified as absent or present. The agreement between the two graders was $\kappa=75.6 \%$ (95\%CI $55.6 \%$ to $95.76 \%$ ).

The eligible eyes were randomly assigned into two groups: the combined (IVB/intravitreal injection of fasudil (IVF)) group and the monotherapy (IVB) group. The monotherapy group received only intravitreal injection of $1.25 \mathrm{mg} / 0.05 \mathrm{~mL}$ bevacizumab (Avastin, made for F. Hoffmann-La Roche, Basel, Switzerland, by Genentech, San Francisco, USA). In the combined group, however, intravitreal injection of $50 \mu \mathrm{M}$ per $\mathrm{L} / 0.05 \mathrm{~mL}$ fasudil (Asahi Kasei Pharma, Tokyo, Japan) and $1.25 \mathrm{mg} / 0.05 \mathrm{~mL}$ bevacizumab was performed with two different syringes and via separate routes, followed by anterior chamber paracentesis. Intravitreal injections were performed under sterile conditions 3.5 and $4 \mathrm{~mm}$ from the limbus in pseudophakic and phakic eyes, respectively.

In each group, three consecutive intravitreal injections were performed monthly. Then, follow-up was done up to month 6 with no further injections. At months 3 and 6, BCVA and CMT were recorded and compared with the baseline measurements of each group. Based on the evaluation performed at month 6, retreatment with IVB injection was done if needed.

\section{Main outcome measures}

The primary outcome measure of this study was the mean change in BCVA at month 6 compared with the baseline value. The mean change in BCVA at month 3 , the per cent of eyes gaining 15 ETDRS letters or more at months 3 and 6 and the mean changes in CMT at months 3 and 6 were secondary outcome measures. In addition, ocular complications especially intraocular inflammation and increased intraocular pressure and systemic side effects mainly hypotension and thromboembolic events were considered as secondary outcome measures.

\section{Sample size}

To have a power of $90 \%$ to detect a difference of 10 ETDRS letters between the two study groups when the SD of BCVA in both groups was assumed to be 10 ETDRS letters, 21 eyes in each group was needed. Anticipating possible loss to follow-up, a total of 44 eyes (22 per group) were recruited and each eye was randomly assigned to one of two parallel groups in a 1:1 allocation ratio.

\section{Randomisation}

The permuted-block randomisation method was used, with the block length varied from 2 to 6 . Random allocation was performed by a biostatistician blinded to the clinical information. The random allocation sequence itself was generated by a computer program and concealed from the investigators.

\section{Blinding}

BCVA evaluation and OCT were performed by a trained optometrist who was blinded to both the randomisation and the findings of the previous follow-up examinations. In addition, statistical analysis was performed on the coded data by a biostatistician who was blinded to the treatment conditions.

\section{Statistical analysis}

Mean, SD, frequency and per cent were used to present data. To compare variables at baseline, the t-test, Mann-Whitney $\mathrm{U}$ test, $\chi^{2}$ and Fisher's exact test were used where appropriate. In addition, the changes in BCVA and CMT from baseline were compared between the two groups by t-tests. Analysis of covariance (ANCOVA) was used to compare the values of BCVA and CMT adjusted for the baseline at 3 and 6 months. To compare the per cent of eyes gaining 15 ETDRS letters or more between the two groups, we used log-binomial regression analysis. In addition, a generalised estimating equation (GEE) model was used to compare the results throughout the study period, adjusting for the baseline values and other possible confounder variables. Changes within groups were evaluated by a linear mixed model, and multiple comparisons were performed by the Bonferroni method. All statistical analyses were performed in SPSS (V.23.0, IBM). P values $<0.05$ were considered statistically significant.

\section{RESULTS}

A total of 44 eyes of 44 patients were assessed for eligibility. Of 44 patients, $22(50 \%)$ were male. Patients' mean age was $57.9 \pm 8.4$ years (range: $44-75$ years). Two patients (two eyes) of the IVB group did not complete the 6-month follow-up; therefore, statistical analysis was performed on 42 eyes.

There was no statistically significant difference between the two groups regarding baseline parameters (table 1). The mean baseline BCVA in the IVB/IVF group was $48 \pm 17$ ETDRS letters (approximately equal to 20/120 Snellen visual acuity) which significantly improved at month $3(60 \pm 10$ ETDRS letters; equal to $20 / 60 ; \mathrm{p}<0.001)$ and month $6(62 \pm 12$ ETDRS letters; equal to $20 / 60 ; p<0.001)$. In the IVB group, however, the improvement

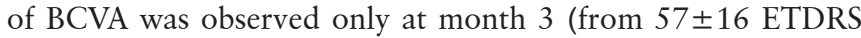
letters (20/70 Snellen visual acuity) at baseline to $63 \pm 11$ ETDRS letters $(20 / 60$ Snellen visual acuity) at month $3(p<0.001))$. No significant visual improvement was noticed at month 6 compared with baseline in this group $(\mathrm{p}>0.99)$ (table 2). Improvement of mean BCVA at months 3 and 6 was significantly higher in the IVB/IVF group than in the IVB group $(\mathrm{p}=0.008$ and $\mathrm{p}<0.001$, respectively). Of 22 eyes in the IVB/IVF group, 9 (40.9\%) eyes gained $\geq 15$ ETDRS letters at month 3 ; the corresponding value was 4 out of 20 eyes $(20.0 \%)$ in the IVB group. This visual gain increased to $12(54.5 \%)$ eyes in the IVB/IVF group but decreased to $2(10.0 \%)$ in the IVB group at month 6 (relative risk $=5.4$, $95 \%$ CI 1.2 to $24.4, \mathrm{p}=0.026$ ), (table 2). Between months 3 and 6 , mean BCVA significantly decreased by $5 \pm 7$ ETDRS letters in the IVB group $(p=0.002)$, while no significant deterioration was observed in the IVB/IVF group ( $p>0.99$; figure 1$)$.

CMT changes in both groups were in line with BCVA findings at both time points. Although CMT significantly decreased in both groups at month $3(\mathrm{p}=0.006, \mathrm{p}<0.001)$, this reduction was statistically significantly more pronounced in the IVB/IVF group than in the IVB group $(p<0.001)$ (table 3$)$. At month 6 , the mean 


\begin{tabular}{|c|c|c|c|c|}
\hline \multirow[b]{2}{*}{ Parameter } & \multirow[b]{2}{*}{ Total } & \multicolumn{2}{|l|}{ Group } & \multirow[b]{2}{*}{$P$ values } \\
\hline & & IVB & IVB/IVF & \\
\hline \multicolumn{5}{|l|}{ Age (years) } \\
\hline Mean \pm SD & $57.9 \pm 8.4$ & $58.9 \pm 8.8$ & $57.1 \pm 8.2$ & $0.568^{*}$ \\
\hline Median (range) & $57.5(44-75)$ & $60(44-75)$ & $57(44-75)$ & \\
\hline \multicolumn{5}{|l|}{ Sex } \\
\hline Male & $22(52.4 \%)$ & $12(60.0 \%)$ & $10(45.5 \%)$ & $0.346 t$ \\
\hline Female & $20(47.6 \%)$ & $8(40.0 \%)$ & $12(54.5 \%)$ & \\
\hline \multicolumn{5}{|l|}{ Stage of DR } \\
\hline Moderate NPDR & $20(47.7 \%)$ & $13(66.7 \%)$ & $7(31.8 \%)$ & $0.121 \ddagger$ \\
\hline Severe NPDR & $12(28.5 \%)$ & $3(16.7 \%)$ & $9(40.9 \%)$ & \\
\hline Regressed PDR & $10(23.8 \%)$ & $4(16.7 \%)$ & $6(27.3 \%)$ & \\
\hline \multicolumn{5}{|l|}{ Macular ischaemia } \\
\hline No & $27(63.3 \%)$ & $15(75.0 \%)$ & $12(55.0 \%)$ & $0.442 \S$ \\
\hline Yes & $15(36.7 \%)$ & $5(25.0 \%)$ & $10(45.0 \%)$ & \\
\hline
\end{tabular}

Previous IVB injections

(\%)

\begin{tabular}{|c|c|c|c|c|}
\hline No & $14(33.3 \%)$ & $6(30 \%)$ & $8(36.4 \%)$ & $0.662 \dagger$ \\
\hline Yes & $28(66.7 \%)$ & $14(70 \%)$ & $14(63.6 \%)$ & \\
\hline \multicolumn{5}{|c|}{ Previous IVB injections (n) } \\
\hline Mean \pm SD & $2.2 \pm 2.1$ & $2.6 \pm 2.5$ & $2 \pm 1.9$ & $0.447 \ddagger$ \\
\hline Median (range) & $2(0-8)$ & $2(0-8)$ & $1(0-6)$ & \\
\hline \multicolumn{5}{|c|}{ Previous MPC sessions } \\
\hline Mean \pm SD & $0.6 \pm 1.3$ & $0.5 \pm 1.4$ & $0.7 \pm 1.2$ & $0.523 \ddagger$ \\
\hline Median (range) & $0(0-5)$ & $0(0-5)$ & $0(0-4)$ & \\
\hline \multicolumn{5}{|c|}{ Previous IVT injections (\%) } \\
\hline No & $38(90.5 \%)$ & $16(77.8 \%)$ & $22(100.0 \%)$ & $0.142 \S$ \\
\hline Yes & $4(9.5 \%)$ & $4(22.2 \%)$ & $0(0.0 \%)$ & \\
\hline \multicolumn{5}{|l|}{$\mathrm{FBS}(\mathrm{mg} / \mathrm{dL})$} \\
\hline Mean \pm SD & $184.4 \pm 75.3$ & $181.3 \pm 69.6$ & $186.7 \pm 81.5$ & $0.854^{*}$ \\
\hline Median (range) & $167(82-359)$ & 163(104-359) & $167(82-359)$ & \\
\hline \multicolumn{5}{|l|}{ Creatinine (mg/dL) } \\
\hline Mean \pm SD & $1.09 \pm 0.27$ & $1.1 \pm 0.16$ & $1.08 \pm 0.33$ & $0.831^{*}$ \\
\hline Median (range) & $1(0.6-1.83)$ & $1.05(0.88-1.4)$ & $1(0.6-1.83)$ & \\
\hline \multicolumn{5}{|l|}{$\mathrm{HbA1c}$} \\
\hline Mean \pm SD & $7.9 \pm 1.4$ & $7.4 \pm 1$ & $8.2 \pm 1.5$ & $0.188^{*}$ \\
\hline Median (range) & $7.9(5.8-10.3)$ & $7.5(5.8-8.8)$ & $8.7(6.3-10.3)$ & \\
\hline \multicolumn{5}{|l|}{ BUN (mg/dL) } \\
\hline Mean \pm SD & $22.69 \pm 5.41$ & $25.93 \pm 3.58$ & $20.25 \pm 5.62$ & $0.190^{*}$ \\
\hline Median (range) & 23(13-29) & $26.8(22-29)$ & $21(13-26)$ & \\
\hline
\end{tabular}

*Based on t-test.

${ }^{\dagger}$ Based on $\chi^{2}$ test.

${ }^{\ddagger}$ Based on Mann-Whitney test.

${ }^{\S}$ Based on Fisher's exact test.

$B U N$, blood urea nitrogen; DR, diabetic retinopathy; $F B S$, fasting blood sugar;

IVB, intravitreal injection of bevacizumab;IVB/IVF, intravitreal injection of both bevacizumab and fasudil; IVT, intravitreal injection of triamcinolone acetonide; MPC, macular photocoagulation; NPDR, non-proliferative diabetic retinopathy; PDR, proliferative diabetic retinopathy.

CMT reduction in the IVB group was no longer statistically significant compared with the baseline value $(p>0.99)$. In the IVB/IVF group, however, this statistically significant reduction persisted $(\mathrm{p}<0.001)$ (table 3). Between months 3 and 6, mean CMT changed in opposite directions in the two groups: it showed an increase in the IVB group from $439 \pm 112$ to $509 \pm 120 \mu \mathrm{m}$ $(p=0.018)$, whereas its decreasing course continued with a reduction from $373 \pm 100$ to $356 \pm 119 \mu \mathrm{m}(\mathrm{p}=0.664)$ in the IVB/ IVF group (figure 2).
According to GEE analysis, the IVB/IVF group showed 5.2 ETDRS letters more visual improvement (95\%CI 1.1 to 9.3, $\mathrm{p}=0.013)$ and $107 \mu \mathrm{m}$ more CMT reduction $(95 \%$ CI 54 to 160 , $\mathrm{p}<0.001$ ) than the IVB group over the 6 -month study period.

The simultaneous effects of all baseline parameters on BCVA and CMT were also evaluated using GEE analysis, which showed a positive relationship between the baseline BCVA and the BCVA assessed throughout the study period $(p<0.001)$. In addition, eyes with macular ischaemia showed, on average, 7.3 (95\% CI 5.9 to 8.7, p < 0.001) ETDRS letters lower BCVA than eyes with no macular ischaemia, adjusted for the factors mentioned in table 1.

Regarding the CMT, the baseline CMT was positively related to the CMT measured throughout the study period $(\mathrm{p}<0.001)$. CMT was $83 \mu \mathrm{m}(95 \%$ CI 47 to $120, \mathrm{p}<0.001)$ higher in eyes with macular ischaemia than in eyes with no macular ischaemia, adjusted for all baseline parameters. Other factors were not significantly related to BCVA and CMT during the study period $(\mathrm{p}>0.05)$.

An exploratory analysis of the subgroup with macular ischaemia revealed that visual improvement in the IVB group was $4 \pm 7$ ETDRS letters compared with $12 \pm 5$ ETDRS letters in the IVB/IVF group at month 3 , with a statistically significant difference between the two groups $(p=0.020)$. At month 6 , the IVB group lost $7 \pm 8$ ETDRS letters, while the IVB/IVF group gained $11 \pm 7$ ETDRS letters compared with the baseline $(\mathrm{p}<0.001)$. CMT changes in this subgroup were consistent with the BCVA changes comparing the two groups at month $6(\mathrm{p}=0.007)$. No ocular or systemic adverse events were observed in the study groups.

\section{DISCUSSION}

This pilot randomised clinical trial examining severe cases of centre-involving DME demonstrated significant improvements of BCVA and reductions of CMT after three intravitreal injections in both the bevacizumab monotherapy and combined bevacizumab and fasudil groups 3 months after the first injection. However, the beneficial effects of treatment on both BCVA and CMT were statistically and clinically more significant in the combined group than in the monotherapy group. The treatment effect decreased gradually in the monotherapy group and returned to near-baseline values in terms of BCVA and CMT within 3 months after the cessation of intravitreal injection. However, the beneficial therapeutic effects on BCVA and CMT persisted up to month 6 in eyes receiving combined IVB and fasudil. In addition to the difference in mean BCVA changes in favour of the combined group, the proportion of cases gaining 15 or more ETDRS letters was clinically more pronounced in the combined group than in the monotherapy group at both time points, reaching a statistically significant difference at month 6 .

DME has a complex pathogenesis. ${ }^{2}$ In addition to the upregulation of VEGF, inflammation has also a crucial role in increasing retinal vascular permeability in patients with diabetes. ${ }^{13-15}$ In vitro and in vivo studies have shown that inhibition of the ROCK pathway via intravitreal injection of fasudil effectively suppresses increased intercellular adhesion molecule- 1 (ICAM-1) expression and leucocyte adhesion to retinal endothelial cells in diabetic animals. ${ }^{16}{ }^{17}$ Moreover, fasudil prevents endothelial damage even when leucocytes are firmly adhered to the endothelium via restoration of endothelial nitric oxide synthase (eNOS) phosphorylation. ${ }^{18}$

The 3-month results of the current RCT showed significant improvement of anatomical and functional outcomes compared 
Table 2 Best-corrected visual acuity (ETDRS) after intravitreal injection in the IVB and IVB/IVF groups

\begin{tabular}{|c|c|c|c|c|c|c|c|}
\hline \multirow[b]{2}{*}{ Time point } & \multirow[b]{2}{*}{ Total } & \multicolumn{2}{|l|}{ Group } & \multirow[b]{2}{*}{ Difference } & \multicolumn{2}{|l|}{$95 \% \mathrm{Cl}$} & \multirow[b]{2}{*}{$P$ values } \\
\hline & & IVB & IVB/IVF & & Lower & Upper & \\
\hline \multicolumn{8}{|l|}{ Baseline } \\
\hline Mean \pm SD & $52 \pm 19$ & $57 \pm 16$ & $48 \pm 17$ & 9 & -1 & 19 & $0.086^{*}$ \\
\hline \multicolumn{8}{|l|}{ Month 3} \\
\hline Mean \pm SD & $62 \pm 11$ & $63 \pm 11$ & $60 \pm 10$ & -7 & -12 & -2 & $0.003 t$ \\
\hline \multicolumn{8}{|l|}{ Change (baseline-3) } \\
\hline Mean \pm SD & $9 \pm 7$ & $7 \pm 6$ & $12 \pm 6$ & -5 & -9 & -1 & $0.008^{*}$ \\
\hline$\geq 15$ ETDRS letters & $13(31.0 \%)$ & $4(20.0 \%)$ & $9(40.9 \%)$ & -20.9 & -49.7 & 7.9 & $0.150 \ddagger$ \\
\hline P-Within§ & & $<0.001$ & $<0.001$ & & & & \\
\hline \multicolumn{8}{|l|}{ Month 6} \\
\hline Mean \pm SD & $60 \pm 13$ & $58 \pm 13$ & $62 \pm 12$ & -13 & -24 & -1 & $0.029 t$ \\
\hline \multicolumn{8}{|l|}{ Change (baseline-6) } \\
\hline Mean $\pm S D$ & $7 \pm 11$ & $1 \pm 10$ & $13 \pm 9$ & -12 & -18 & -6 & $<0.001^{*}$ \\
\hline$\geq 15$ ETDRS letters & $14(33.3 \%)$ & $2(10.0 \%)$ & $12(54.5 \%)$ & -44.5 & -70.7 & -18.4 & $0.006 \ddagger$ \\
\hline P-within§ & & $>0.99$ & $<0.001$ & & & & \\
\hline
\end{tabular}

${ }^{*}$ Based on t-test.

†Adjusted for the baseline, based on analysis of covariance.

$\ddagger$ Based on logistic regression.

$\S B$ Based on linear mixed model, multiple comparison considered by Bonferroni method.

IVB, intravitreal injection of bevacizumab; IVB/IVF, intravitreal injection of both bevacizumab and fasudil.

with the baseline in both study groups; however, the beneficial effects of treatment were significantly more prominent in the combined group compared with the monotherapy group. More importantly, after the cessation of injections, BCVA and CMT returned to the baseline in the monotherapy group, while the therapeutic effects persisted up to 6 months in the combined group. These findings may be due to the additional effects of fasudil via a VEGF-independent mechanism. The increased sustainability of the treatment effects in addition to the enhanced functional and anatomical improvements may be the most pronounced aspects of this type of combination therapy.

The results of our study revealed that eyes with macular ischaemia had less favourable visual outcomes than other eyes with DME, which is in agreement with previous studies. ${ }^{19} 20$ Eyes with macular ischaemia which received the combination of IVB and IVF experienced significantly better visual and anatomical outcomes than eyes that underwent IVB injection alone. This finding may be attributable to the ROCK inhibition-induced

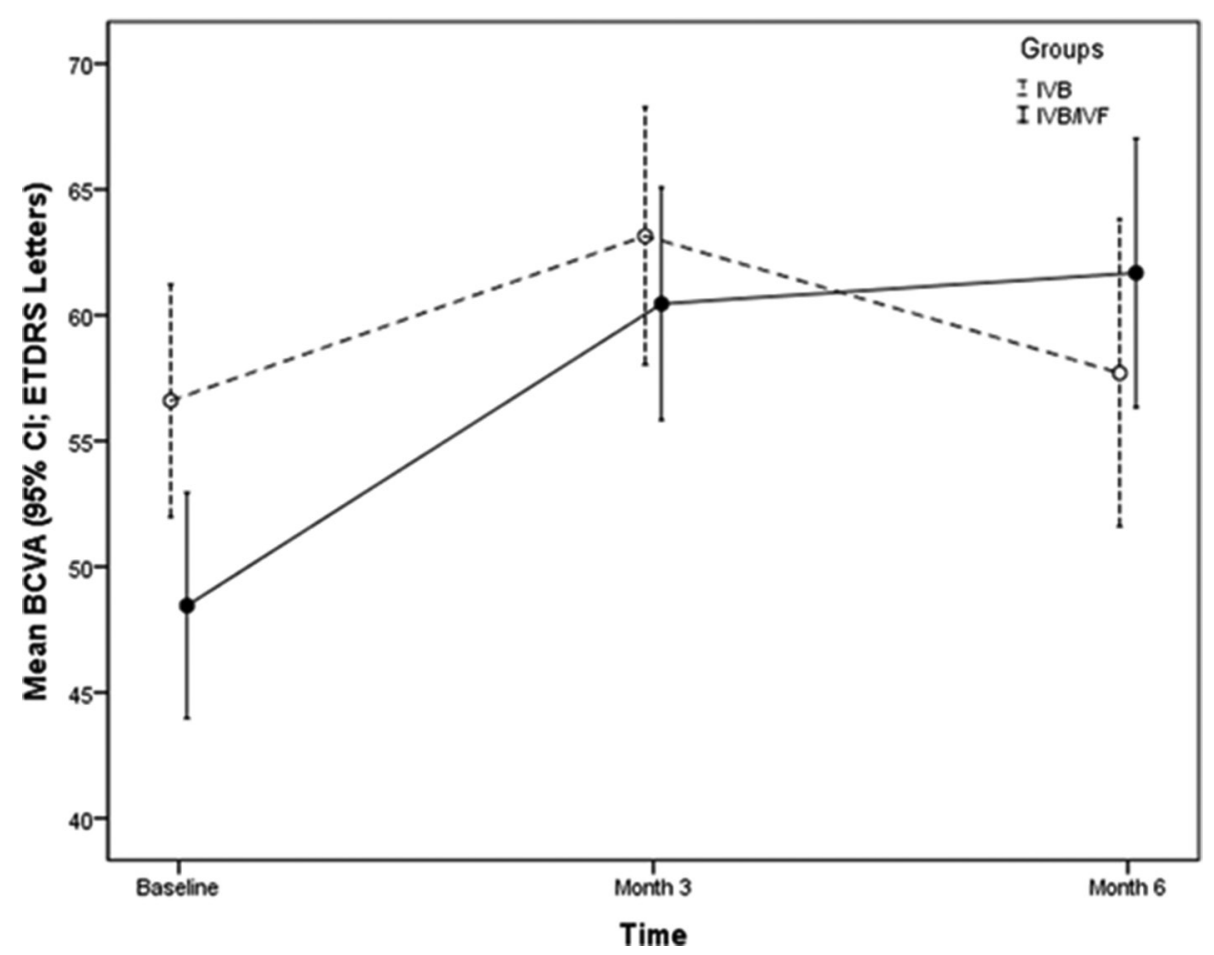

Figure 1 Mean and its $95 \% \mathrm{Cl}$ for the best-corrected visual acuity (BCVA) of the two groups at 3-month and 6-month follow-ups. IVB, intravitreal bevacizumab; IVF, intravitreal injection of fasudil. 
Table 3 Central macular thickness after intravitreal injection in the IVB and IVB/IVF groups

\begin{tabular}{|c|c|c|c|c|c|c|c|}
\hline \multirow[b]{2}{*}{ Parameter } & \multirow[b]{2}{*}{ Total } & \multicolumn{2}{|l|}{ Group } & \multirow[b]{2}{*}{ Difference } & \multicolumn{2}{|l|}{$95 \% \mathrm{Cl}$} & \multirow[b]{2}{*}{$P$ values } \\
\hline & & IVB & IVB/IVF & & Lower & Upper & \\
\hline \multicolumn{8}{|l|}{ Baseline } \\
\hline Mean \pm SD & $528 \pm 100$ & $511 \pm 96$ & $543 \pm 102$ & -33 & -94 & 30 & $0.558^{*}$ \\
\hline \multicolumn{8}{|l|}{ Month 3} \\
\hline Mean \pm SD & $405 \pm 109$ & $439 \pm 112$ & $373 \pm 100$ & 95 & 51 & 139 & $<0.001 \dagger$ \\
\hline \multicolumn{8}{|c|}{ Change (baseline-3) } \\
\hline Mean \pm SD & $-123 \pm 88$ & $-72 \pm 83$ & $-170 \pm 64$ & 98 & 51 & 144 & $<0.001^{*}$ \\
\hline P-within $\ddagger$ & & 0.006 & $<0.001$ & & & & \\
\hline \multicolumn{8}{|l|}{ Month 6} \\
\hline Mean $\pm S D$ & $429 \pm 141$ & $509 \pm 120$ & $356 \pm 119$ & 192 & 136 & 248 & $<0.001 \dagger$ \\
\hline \multicolumn{8}{|c|}{ Change (baseline-6) } \\
\hline Mean $\pm S D$ & $-100 \pm 136$ & $0 \pm 87$ & $-191 \pm 105$ & 191 & 129 & 253 & $<0.001^{*}$ \\
\hline P-within $\ddagger$ & & $>0.99$ & $<0.001$ & & & & \\
\hline
\end{tabular}

${ }^{*}$ Based on t-test.

†Adjusted for the baseline, based on analysis of covariance.

$\ddagger$ Based on linear mixed model, multiple comparison considered by Bonferroni method.

IVB, intravitreal injection of bevacizumab; IVB/IVF, intravitreal injection of both bevacizumab and fasudil.

vasodilation secondary to increased eNOS. ${ }^{21}$ In addition, ROCK inhibition may reduce the endothelial cell damage by adhered leucocytes, explaining the short-term beneficial effects of fasudil in eyes with DME associated with macular ischaemia.

Previous in vivo studies showed that intravitreal injection of up to $100 \mu \mathrm{M} / \mathrm{L}$ fasudil in rat eyes did not cause apparent electrophysiological or morphological changes in the retinal tissues. $^{22}$ In addition, our previous case series revealed the safety of intravitreal injection of fasudil in patients with diabetes. ${ }^{9} 10$ These studies showed no significant intraocular inflammation or retinal toxicity in eyes receiving intravitreal fasudil. In addition, these studies demonstrated that combined intravitreal injection of bevacizumab and fasudil resulted in a significant visual improvement and CMT reduction in eyes with severe and refractory DME. ${ }^{9}{ }^{10}$ Similarly, no adverse events were observed in patients undergoing intravitreal injection of combined bevacizumab and fasudil in the current study.

In order not to deprive the patients of an established treatment, this pilot RCT was designed to assess the additive effects of an intravitreal ROCK inhibitor in combination with a VEGF inhibitor in the first step. With the observation of its beneficial additive effects, the efficacy of intravitreal fasudil alone in the treatment of DME may be evaluated in the future studies.

The shortcomings of this study included lack of FAG data at months 3 and 6 , short follow-up period and no evaluation of the possible effects of combined fasudil and bevacizumab

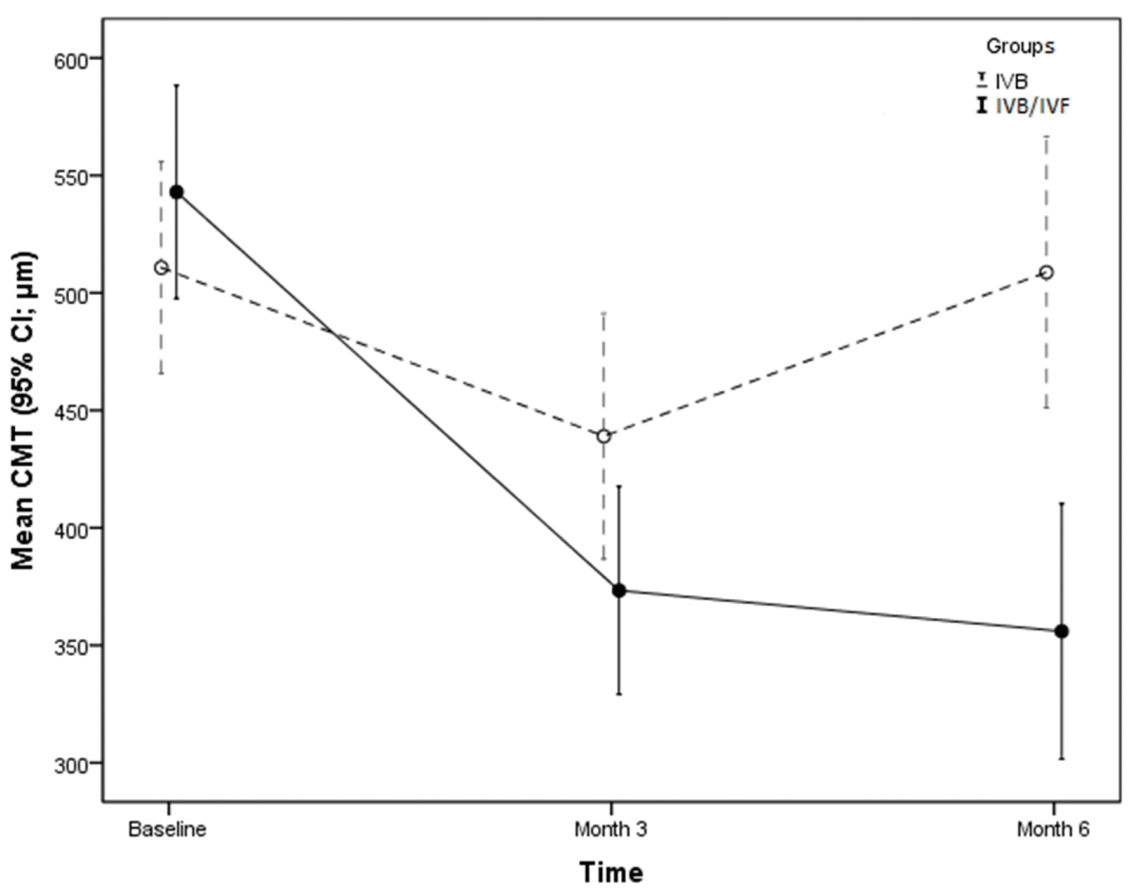

Figure 2 Mean and its $95 \% \mathrm{Cl}$ for the central macular thickness (CMT) of the two groups at 3-month and 6-month follow-ups. IVB, intravitrea linjection of bevacizumab; IVF, intravitreal injection of fasudil. 
on the superficial and deep macular plexus using OCT angiography.

In summary, this pilot RCT showed that using an intravitreal ROCK inhibitor as an adjunct to IVB is likely to promote the efficacy and increase the durability of anti-VEGF drugs in the treatment of severe DME. Larger clinical trials with longer follow-ups are recommended. Further studies are also needed to assess the pharmacokinetics of intravitreal fasudil.

\section{Author affiliations}

'Ophthalmic Research Center, Shahid Beheshti University of Medical Sciences, Tehran, Iran

${ }^{2}$ Ocular Tissue Engineering Research Center, Shahid Beheshti University of Medical Sciences, Tehran, Iran

${ }^{3}$ Molecular Biomarkers Nono-Imaging Laboratory, Brigham and Women's Hospital, Boston, Massachusetts, USA

${ }^{4}$ Department of Radiology, Harvard Medical School, Boston, Massachusetts, USA

${ }^{5}$ Ophthalmic Epidemiology Research Center, Shahid Beheshti University of Medical Sciences, Tehran, Iran

${ }^{6}$ Department of Ophthalmology, Graduate School of Medical Sciences, Kyushu University, Kyushu, Japan

${ }^{7}$ Berner Augenklinik am Lindenhofspital, Swiss Eye Institute and Clinic for Vitreoretinal Diseases, Bern, Switzerland

${ }^{8}$ Department of Epidemiology and Biostatistics, Tehran University of Medical Sciences, Tehran, Iran

Contributors $\mathrm{HA}$, RN: design, acquisition and interpretation of data, drafting, revising and final approval of the manuscript. AH-M, SN and SZ: design, revising and final approval of the manuscript. HS: design, acquisition and interpretation of data, drafting and final approval of the manuscript. MY: design, analysis and interpretation of data and final approval of the manuscript. ZT: design, drafting, revising and final approval of the manuscript. SA: acquisition of data, drafting and final approval of the manuscript.

Funding The authors have not declared a specific grant for this research from any funding agency in the public, commercial or not-for-profit sectors.

Competing interests None declared.

Patient consent Not required.

Ethics approval Ethics Committee, Ophthalmic Research Center, Shahid Beheshti University of Medical Sciences (IR.SBMU.ORC.REC.1392.1).

Provenance and peer review Not commissioned; externally peer reviewed.

\section{REFERENCES}

1 Ding J, Wong TY. Current epidemiology of diabetic retinopathy and diabetic macular edema. Curr Diab Rep 2012;12:346-54.

2 Nourinia R, Soheilian M. State of the art management of diabetic macular edema. World J Ophthalmol 2015;5:55-72.
3 Joussen AM, Poulaki V, Le ML, et al. A central role for inflammation in the pathogenesis of diabetic retinopathy. Faseb J 2004;18:1450-2.

4 Deissler $\mathrm{H}$, Deissler $\mathrm{H}$, Lang $\mathrm{S}$, et al. VEGF-induced effects on proliferation, migration and tight junctions are restored by ranibizumab (Lucentis) in microvascular retinal endothelial cells. Br J Ophthalmol 2008;92:839-43.

5 Wójciak-Stothard B, Williams L, Ridley AJ. Monocyte adhesion and spreading on human endothelial cells is dependent on Rho-regulated receptor clustering. I Cell Biol 1999:145:1293-307.

6 Arita R, Nakao S, Kita T, et al. A key role for ROCK in TNF- $\alpha$-mediated diabetic microvascular damage. Invest Ophthalmol Vis Sci 2013;54:2373-83.

7 Arita R, Hata Y, Nakao S, et al. Rho kinase inhibition by fasudil ameliorates diabetesinduced microvascular damage. Diabetes 2009;58:215-26.

8 Nourinia R, Nakao S, Zandi S, et al. ROCK inhibitors for the treatment of ocular diseases. Br J Ophthalmol 2017:bjophthalmol-2017-310378.

9 Ahmadieh H, Nourinia R, Hafezi-Moghadam A. Intravitreal fasudil combined with bevacizumab for persistent diabetic macular edema: a novel treatment. JAMA Ophthalmol 2013;131:923-4.

10 Nourinia R, Ahmadieh H, Shahheidari MH, et al. Intravitreal fasudil combined with bevacizumab for treatment of refractory diabetic macular edema; a pilot study. J Ophthalmic Vis Res 2013;8:337-40.

11 Panozzo G, Parolini B, Gusson E, et al. Diabetic macular edema: an OCT-based classification. Semin Ophthalmol 2004;19(1-2):13-20.

12 Douvali M, Chatziralli IP, Theodossiadis PG, et al. Effect of macular ischemia on intravitreal ranibizumab treatment for diabetic macular edema. Ophthalmologica 2014;232:136-43.

13 Zhang $X$, Zeng $\mathrm{H}$, Bao $\mathrm{S}$, et al. Diabetic macular edema: new concepts in pathophysiology and treatment. Cell Biosci 2014;4:27.

14 Funatsu H, Noma H, Mimura T, et al. Association of vitreous inflammatory factors with diabetic macular edema. Ophthalmology 2009;116:73-9.

15 Noda K, Nakao S, Zandi S, et al. Retinopathy in a novel model of metabolic syndrome and type 2 diabetes: new insight on the inflammatory paradigm. Faseb J 2014:28:2038-46.

16 Del Maschio A, Zanetti A, Corada M, et al. Polymorphonuclear leukocyte adhesion triggers the disorganization of endothelial cell-to-cell adherens junctions. J Cell Biol 1996;135:497-510.

17 Barreiro 0, Yanez-Mo M, Serrador JM, et al. Dynamic interaction of VCAM-1 and ICAM-1 with moesin and ezrin in a novel endothelial docking structure for adherent leukocytes. J Cell Biol 2002;157:1233-45.

18 Ming XF, Viswambharan H, Barandier C, et al. Rho GTPase/Rho kinase negatively regulates endothelial nitric oxide synthase phosphorylation through the inhibition of protein kinase B/Akt in human endothelial cells. Mol Cell Biol 2002;22:8467-77.

19 Sim DA, Keane PA, Zarranz-Ventura J, et al. The effects of macular ischemia on visual acuity in diabetic retinopathy. Invest Ophthalmol Vis Sci 2013;54:2353-60.

20 Sim DA, Keane PA, Zarranz-Ventura J, et al. Predictive factors for the progression of diabetic macular ischemia. Am J Ophthalmol 2013:156:684-92.

21 Okamura N, Saito M, Mori A, et al. Vasodilator effects of fasudil, a Rho-kinase inhibitor, on retinal arterioles in stroke-prone spontaneously hypertensive rats. J Ocul Pharmacol Ther 2007; 23:207-12.

22 Kita T, Hata Y, Arita R, et al. Role of TGF-beta in proliferative vitreoretinal diseases and ROCK as a therapeutic target. Proc Natl Acad Sci U S A 2008;105:17504-9. 